\section{Encefalitis autoinmune en pediatría}

\section{Autoimmune encephalitis in pediatrics.}

García-Beristáin JC ${ }^{1}$, Barragán-Pérez $E^{2}$, Choperena-Rodríguez $\mathrm{R}^{3}$, ReyesCruz $\mathrm{G}^{4}$

\section{DEFINICIÓN}

La encefalitis es un desorden inflamatorio del encéfalo que deriva en un estado mental alterado, crisis convulsivas, déficits neurológicos focales, acompañado usualmente de signos de inflamación en el líquido cefalorraquídeo y hallazgos en la resonancia magnética que pueden ir desde normalidad hasta anormalidades extensas. ${ }^{1}$ La encefalitis puede ocurrir como resultado de una infección primaria del sistema nervioso central, o bien, por un proceso autoinmune desencadenado por una infección, vacuna o neoplasia oculta. ${ }^{2}$ La encefalitis autoinmune involucra varios tipos de entidades con diferentes fisiopatologías, el entender estas entidades nos ayuda a utilizar los recursos y elementos diagnósticos necesarios, así como la mejor estrategia terapéutica. $^{3}$

\section{EPIDEMIOLOGÍA}

En Estados Unidos se ha estimado que ocurren aproximadamente 20,000 casos de encefalitis por año, y que aproximadamente en $50 \%$ de los casos reportados no se identificaron agentes infecciosos como agentes causales, determinándose en la mayoría una asociación autoinmune. ${ }^{4}$ En México no contamos con datos disponibles respecto a este padecimiento de forma específica. Algunos estudios han sugerido que existe un predomino de presentación en el sexo femenino con un aproximado de $67 \%$ y una edad promedio de 10.1 años. $^{5}$

\section{COMORBILIDADES}

La comorbilidad mayormente descrita han sido teratomas ováricos en más de 1/3 de mujeres adultas con diagnóstico de

\footnotetext{
${ }^{1}$ Adscrito al Departamento de Neurología, Coordinador de la Clínica de Enfermedades Neuroinmunológicas. Fellow AMSA.

2Jefe del Departamento de Neurología del Hospital Infantil de México Federico Gómez.

${ }^{3}$ Adscrita a Consulta externa de Neurología. Fellow AMSA.

${ }^{4}$ Residente de quinto año de Neurología Pediátrica.

Hospital Infantil de México Federico Gómez, Ciudad de México.

Recibido: 27 de febrero del 2017

Aceptado: 25 de marzo del 2017

Correspondencia Juan Carlos García Beristáin beristainjc@gmail.com
}

Este artículo debe citarse como

García-Beristáin JC, Barragán-Pérez E, ChoperenaRodríguez R, Reyes-Cruz G. Encefalitis autoinmune en pediatría. Acta Pediatr Mex. 2017;38(4):274-279. 
encefalitis autoinmune, siendo más común en pacientes en edad reproductiva. ${ }^{6}$ La encefalitis autoinmune también se ha asociado con la presencia de otras neoplasias: tumores pulmonares, timomas, linfomas. ${ }^{7}$ Dichas asociaciones nos obligan a descartar que la encefalitis autoinmune sea un proceso paraneoplásico. ${ }^{7}$

\section{PRESENTACIÓN CLÍNICA}

La mayoría de los pacientes con encefalitis autoinmune no tienden a presentarse clínicamente con un síndrome definido, pero la descripción clásica es de un cuadro subagudo $(<3$ meses de evolución); se describe con alteraciones en la memoria, síntomas psiquiátricos y estado mental alterado $^{7}$ (Cuadro 1). Dentro de las características clínicas más frecuentes destaca la presentación de fiebre con anormalidades psiquiátricas, movimientos anormales y disquinesias orofaciales; estas últimas se presentan con mayor frecuencia en el paciente pediátrico.

En la Figura 1 se muestra la evolución clínica de la encefalitis autoinmune secundaria a auto-anticuerpos contra el receptor de $\mathrm{N}$-metil D-aspartato (anti-NMDA), que por mucho es

Cuadro 1. Criterios diagnósticos de la encefalitis autoinmune

1. Evolución sub-aguda (progresión menor de 3 meses) de déficit de la memoria de trabajo (pérdida de memoria a corto plazo), alteración del estado mental o síntomas psiquiátricos.

2. Uno de los siguientes:

- Hallazgos de focalidad recientes.

- Convulsiones no explicadas por un desorden epiléptico previo.

- Pleocitosis en el líquido cefalorraquídeo (leucocitosis en más de 5 cel por $\mathrm{mm}^{3}$ ).

- Hallazgos de resonancia magnética sugestivos de encefalitis.

3. Exclusión de otras causas alternativas.

Adaptado de Graus F, Titulear MJ, Balu R, Benseler S et al. A clinical approach to diagnosis of autoinmune encephalitis. Lancet Neurol. 2015;15:391-404. la encefalitis autoinmune más frecuente en pediatría. ${ }^{1,8}$ La referencia médica debe ser de inmediato ante los datos de encefalitis con antecedente de infección respiratoria, ya que es necesario el abordaje con punción lumbar, resonancia magnética, así como detección de anticuerpos específicos y paneles virales según sea el caso. Comúnmente esto se realiza en hospitales de tercer nivel o institutos nacionales de salud al igual que el tratamiento, el cual será proporcionado por las mismas.

\section{ABORDAJE DIAGNÓSTICO}

Ante un cuadro de sospecha debemos realizar estudios de imagen, electroencefalograma y punción lumbar. Los hallazgos clínicos asociados con alteraciones en el líquido cefalorraquídeo, como pleocitosis, presentan un aumento de proteínas y en un $60 \%$ se encuentran bandas oligoclonales o índice de IgG elevado; esto en alrededor de dos tercios de los pacientes. También se presentan hallazgos en la resonancia magnética de encéfalo de encefalitis (hiperintensidades en regiones temporales o frontales), lo cual orienta al diagnóstico. ${ }^{7} \mathrm{Al}$ momento de realizarse un electroencefalograma en pacientes con encefalitis autoinmune se observa actividad delta en regiones temporales, o actividad delta rítmica generalizada con actividad rápida superpuesta (delta brush), encontrándose un electroencefalograma anormal hasta en $90 \%$ de los casos. ${ }^{5,9}$ La tomografía computada con emisión de positrones puede mostrar cambios hipo o hipermetabólicos en diversas áreas del cerebro de pacientes con cuadro clínico sugestivo, pero sin hallazgos en resonancia magnética. ${ }^{1,9}$

En el caso de la encefalitis por anticuerpos anti-NMDA el cuadro se caracteriza por manifestaciones neuropsiquiátricas, epilepsia refractaria, estado epiléptico y movimientos anormales (e.g. disquinesias orofaciales). ${ }^{10}$ Después del tratamiento, o en las etapas avanzadas de la 


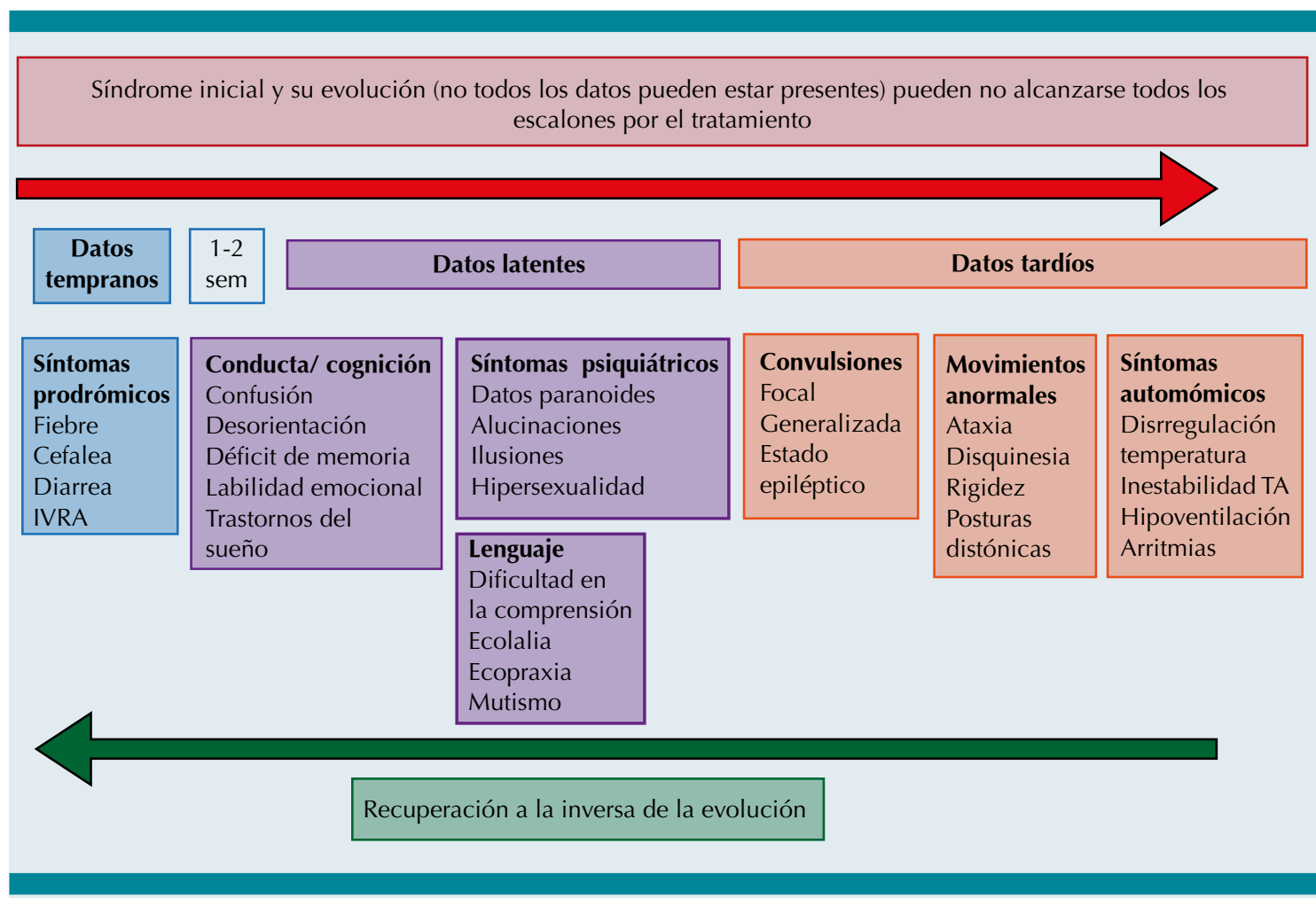

Figura 1. Datos clínicos tempranos latentes y tardíos en encefalitis anti-N-metil-D-aspartato (NMDA). IVRA: infección de vías respiratorias altas; TA: tensión arterial. Adaptado de Newman M, Blum S, Wong R, Scott J, Prain K, Wilson R, et al. Autoinmuneencephalitis, Internal Medicine Journal. 2016;46(2):148-157.

enfermedad, los anticuerpos anti-NMDA por lo general siguen siendo elevados si no hay mejoría clínica, mientras que los anticuerpos del suero pueden estar disminuidos sustancialmente por la acción de los tratamientos. ${ }^{7,10}$ En la Figura 2 mostramos un algoritmo basado en los hallazgos clínicos en cuanto a la gravedad del síndrome encefálico del paciente, así como los datos paraclínicos esenciales.

\section{DIAGNÓSTICO DIFERENCIAL}

Es necesario realizar diagnóstico diferencial con etiologías infecciosas, tóxicas, epilépticas, autoinmunes, etc., las cuales se describen en el Cuadro 2. ${ }^{1,2,7,9}$ Sin embargo, la valoración del paciente por un servicio multidisciplinario, que incluye a neurólogo-pediatría, neuro-radiólogo y neurofisiólogo-pediatra es esencial para el abordaje, manejo o descarte de una encefalitis autoinmune.

\section{TRATAMIENTO}

El tratamiento se encuentra encaminado a la eliminación de los anticuerpos basados en la patogenia de la enfermedad. La primera línea de tratamiento incluye la administración de inmunoglobulina intravenosa, corticoesteroides, plasmaféresis, o combinaciones de las previas; por lo regular, la respuesta efectiva a las terapias comentadas son evidentes en las primeras 4 semanas posteriores a la administración. Los casos refractarios a la primera línea de tratamiento pueden ser tratados con anticuerpos monoclonales contra CD20 (rituximab), o inmunosupresores 


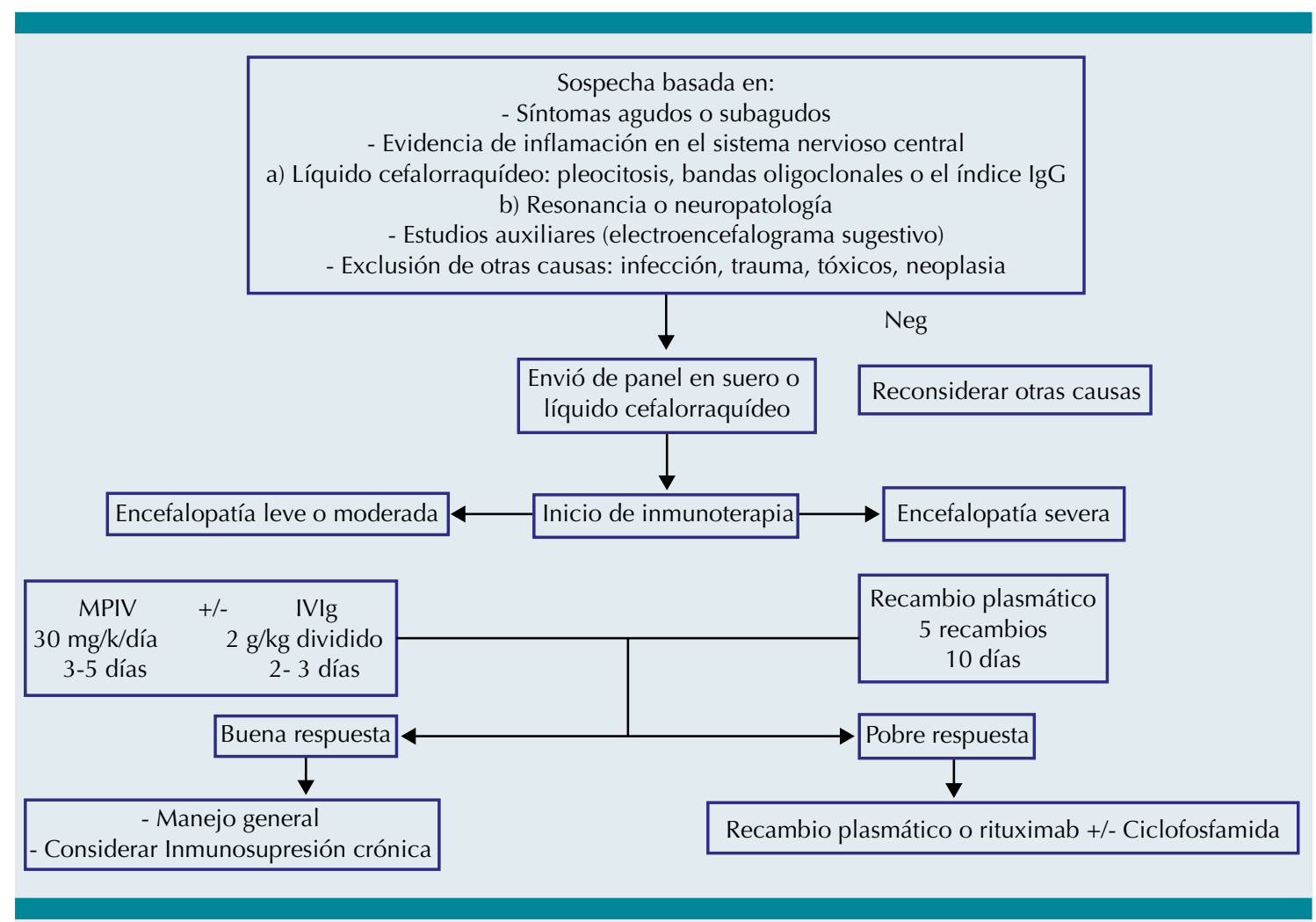

Figura 2. Algoritmo de abordaje y tratamiento en encefalitis autoinmune. MPIV: metilprednisolona intravenosa; IVlg: inmunoglobulina Intravenosa. Adaptado de: Brenton J, Goodkin H. Antibody-Mediated Autoimmune Encephalitis in Childhood. Pediatric Neurology. 2016;60:13-23.

más potentes como ciclofosfamida, e incluso llegar a requerir tratamiento de mantenimiento con distintos inmunosupresores (e.g. ciclofosfamida, azatioprina, micofenolato), la cual en particular recomendamos por al menos 6 meses. ${ }^{11}$ Estos tratamientos se describen en el Cuadro 3.

Por otro lado, es importante dar manejo sintomático a las manifestaciones agudas. El control de movimientos anormales, epilepsia y trastornos psiquiátricos son difíciles de manejar. De manera particular, la agitación psicomotriz manifestada en la encefalitis autoinmune por anticuerpos anti-NMDA puede responder a quetiapina (antipsicótico atípico): iniciando a dosis de $25 \mathrm{mg} /$ día, la cual se puede ir aumentando $25 \mathrm{mg}$ a la semana hasta llegar a un máximo de
300 mg/día. ${ }^{12}$ Del mismo modo, en ocasiones los trastornos del sueño, en especial el insomnio recurrente, en pacientes con encefalitis autoinmune es frecuente, por lo que aunque el manejo con antipsicóticos se encuentra indicado, en ocasiones la inmunoglobulina puede mostrar buenos resultados. ${ }^{13}$

En nuestra experiencia, el manejo de los movimientos anormales puede incluir antiparkinsonianos como trihexifenidilo (iniciando dosis a $5 \mathrm{mg}$ cada 24 horas, con un máximo de $15 \mathrm{mg} /$ día); benzodiacepinas a dosis bajas (clonazepam, alprazolam, lorazepam con dosis de $0.1 \mathrm{mg} / \mathrm{kg} / \mathrm{d}$ ía a $0.6 \mathrm{mg} / \mathrm{kg} /$ día); relajantes musculares del tipo baclofeno (iniciando a 10 mg/día con un máximo de 30 mg/día), los 
Cuadro 2. Diagnósticos diferenciales

\begin{tabular}{|c|c|}
\hline Diagnósticos diferenciales & Estudios a realizar \\
\hline $\begin{array}{l}\text { Etiologías infecciosas } \\
\text { - Encefalitis viral }\end{array}$ & $\begin{array}{l}\text {-Panel viral de LCR para EBV, HHV-6, VZV, VIH, HSV, } \\
\text { enterovirus, arbovirus. }\end{array}$ \\
\hline $\begin{array}{l}\text { - Encefalitis bacteriana } \\
\text { - Encefalitis por espiroquetas }\end{array}$ & $\begin{array}{l}\text { - LCR en búsqueda de Bartonella, Mycoplasma, Ricketssia. } \\
\text { - LCR en búsqueda de Borrelia }\end{array}$ \\
\hline $\begin{array}{l}\text { Tóxicos } \\
\text { - Síndrome neuroléptico maligno } \\
\text { - Ingesta de drogas (alcohol, ketamina, organofosfo } \\
\text { rados) }\end{array}$ & $\begin{array}{l}\text { Solicitar panel toxicológico y estudios de laboratorio } \\
\text { metabólicos (e.g QS, PFH, urea, creatinina) }\end{array}$ \\
\hline $\begin{array}{l}\text { Desórdenes epilépticos } \\
\text { - Estado epiléptico no convulsivo } \\
\text { - Epilepsia de lóbulo temporal } \\
\text { - Encefalopatía epiléptica refractaria inducida por } \\
\text { fiebre (FIRES) }\end{array}$ & $\begin{array}{l}\text { Realizar video electroencefalograma (puede presentar } \\
\text { descargas eléctricas focales, multifocales o generalizadas } \\
\text { continuas o intermitentes) }\end{array}$ \\
\hline $\begin{array}{l}\text { Desórdenes autoinmunes } \\
\text { - Encefalomielitis diseminada aguda } \\
\text { - Vasculitis de SNC } \\
\text { - Enfermedades autoinmunes (síndrome Sjögren, } \\
\text { lupus eritematoso sistémico) }\end{array}$ & $\begin{array}{l}\text { Solicitar estudios inmunológicos, reumatológicos y valoración } \\
\text { por estas mismas sub especialidades, así como } \\
\text { angiorresonancia de cuello y encéfalo (donde pueden } \\
\text { observarse múltiples desórdenes vasculares) }\end{array}$ \\
\hline $\begin{array}{l}\text { Tumorales } \\
\text { - Glioma de SNC } \\
\text { - Metástasis cerebral. }\end{array}$ & $\begin{array}{l}\text { RM de encéfalo (lesiones ocupativas de sistema nerviosos } \\
\text { central) }\end{array}$ \\
\hline $\begin{array}{l}\text { Desórdenes psiquiátricos } \\
\text { - Demencia }\end{array}$ & $\begin{array}{l}\text { Descartar alteraciones estructurales (RM encéfalo), } \\
\text { interconsulta a psiquiatría }\end{array}$ \\
\hline
\end{tabular}

LCR: líquido cefalorraquídeo; EBV: virus Epstein Barr; HHV-6 virus: virus herpes tipo 6; VZV: virus varicela zóster; VIH: virus de inmunodeficiencia humana; HSV: virus herpes simple; EEG: electroencefalograma; RM: resonancia magnética; QS: química

cuales pueden usarse hasta por 8 meses con la reducción gradual al mejorar la sintomatología. ${ }^{9}$ Recientemente, el uso de canabidiol ha dado buena respuesta para el uso de distonías y espasticidad, encontrándose mejoría de estos síntomas a los 180 días posterior del inicio del canabidiol, hasta en un $22 \%$ (pudiéndose iniciar dosis de $3 \mathrm{mg} / \mathrm{k} /$ día con progresión hasta $10 \mathrm{mg} / \mathrm{k} / \mathrm{día}$ ). ${ }^{14}$

\section{SEGUIMIENTO}

En el caso de las encefalitis autoinmunes la inmunosupresión prolongada se evaluará dependiendo de riesgos y beneficios, así como la consideración de que el paciente pudiera presentar una recaída más adelante. ${ }^{2}$ En nuestra experiencia, no hemos encontrado en ningún paciente encefalitis autoinmune asociada con tumoraciones; sin embargo, se considera que en caso de recaída no debe descartarse la posibilidad de neoplasia, la mayoría de los pacientes requieren del manejo de secuelas causado por la encefalitis que puede ir desde epilepsia, problemas motores, cognitivos y del aprendizaje, así como trastornos del sueño de tipo insomnio/hipersomnia; estos últimos, de manera particular, son más frecuentes en encefalitis anti-NMDA. ${ }^{1,4}$ 
García-Beristáin JC et al. Encefalitis autoinmune

Cuadro 3. Manejo de primera y segunda líneas en encefalitis autoinmune

\begin{tabular}{|c|c|}
\hline $\begin{array}{l}\text { Manejo de primera } \\
\text { línea }\end{array}$ & Descripción \\
\hline $\begin{array}{l}\text { Inmunoglobulina } \\
\text { intravenosa }\end{array}$ & $\begin{array}{l}\text { Dosis: } 2 \mathrm{gr} / \mathrm{kg} / \text { dosis total (dividido } \\
\text { en } 2 \text { días de administración) } \\
\text { Contraindicaciones: deficiencia de } \\
\text { lgA, insuficiencia cardiaca, insufi- } \\
\text { ciencia renal, pacientes con riesgo } \\
\text { de trombosis }\end{array}$ \\
\hline Metilprednisolona & $\begin{array}{l}\text { Dosis: } 30 \mathrm{mg} / \mathrm{kg} / \text { dosis (en bolos, } \\
\text { por } 3 \text { a } 5 \text { días) en niños. } 1 \mathrm{~g} / \mathrm{día} \text { en } \\
\text { adultos } \\
\text { Contraindicaciones: proceso infec- } \\
\text { cioso activo }\end{array}$ \\
\hline Plasmaféresis & $\begin{array}{l}\text { Procedimiento estándar: usual- } \\
\text { mente requiere de } 3 \text { a } 5 \text { recambios } \\
\text { plasmáticos } \\
\text { Contraindicaciones: inestabilidad } \\
\text { hemodinámica, angina de pecho, } \\
\text { pericarditis, sepsis }\end{array}$ \\
\hline $\begin{array}{l}\text { Manejo de segunda } \\
\text { línea }\end{array}$ & Descripción \\
\hline Rituximab & $\begin{array}{l}\text { Dosis: } 375 \mathrm{mg} / \mathrm{m}^{2} / \mathrm{sc} \text { una vez a la } \\
\text { semana, por } 4 \text { semanas } \\
\text { Contraindicaciones: infecciones } \\
\text { activas, sepsis }\end{array}$ \\
\hline Azatioprina & $\begin{array}{l}\text { Dosis: } 2-3 \mathrm{mg} / \mathrm{kg} / \text { día vía oral } \\
\text { Contraindicaciones: infecciones } \\
\text { activas, insuficiencia renal crónica }\end{array}$ \\
\hline Micofenolato & $\begin{array}{l}\text { Dosis: } 1 \text {-2 g/día } \\
\text { Contraindicaciones: infecciones } \\
\text { activas }\end{array}$ \\
\hline
\end{tabular}

\section{REFERENCIAS}

1. Armangue T, Petit-Pedrol M, Dalmau J. Autoimmune Encephalitis in Children. Journal of Child Neurology. 2012;27(11):1460-1469.
2. BrentonJGoodkin H. Antibody-Mediated Autoimmune Encephalitis in Childhood. Pediatric Neurology. 2016;60:1323.

3. Lancaster E. The Diagnosis and Treatment of Autoimmune Encephalitis. Journal of Clinical Neurology. 2016;12(1):1.

4. Vollmer TMcCarthy M. Autoimmune encephalitis. Neurology. 2016;86(18):1655-1656.

5. Albert D, Pluto C, Weber A, Vidaurre J, Barbar-Smiley F, Abdul Aziz R et al. Utility of Neurodiagnostic Studies in the Diagnosis of Autoimmune Encephalitis in Children. Pediatric Neurology. 2016;55:37-45.

6. Newman M, Blum S, Wong R, Scott J, Prain K, Wilson R et al. Autoimmune encephalitis. Internal Medicine Journal. 2016;46(2):148-157.

7. Graus F, Titulaer MJ, Balu R, Benseler S, et al. A clinical approach to diagnosis of autoimmune encephalitis. Lancet Neurol. 2016;15:391-404.

8. Leypoldt F, Wandinger K-P, Bien Christian G, Dalmau J. Autoimmune Encephalitis. EurNeurol Rev. 2013;8(1):3137.

9. Lee $\mathrm{S}$. The Laboratory Diagnosis of Autoimmune Encephalitis. Journal of Epilepsy Research. 2016;6(2):45-50.

10. García JC, Barragán E, Choperena R. Anticuerpos antiNMDA asociados a encefalitis por virus herpes simple tipo 1 en pediatría: Reporte de un caso. Revista Mexicana de Neurociencia. 2016;17(6):126-132.

11. Dalmau J, Rosenfeld M .Autoimmune Encephalitis Update. Neuro-Oncology. 2014;16(6):771-778.

12. Sabharwal P, Mahmoudi M, Berberi N, Vasquez B, Friedman D, Kothare S. A Case of Recurrent Insomnia: Extending the Spectrum of Autoimmune Encephalitis. Journal of Clinical Sleep Medicine. 2016;12(05):763-765.

13. Schumacher L, Mann A, MacKenzie J. Agitation Management in Pediatric Males with Anti-N-Methyl-D-Aspartate Receptor Encephalitis. Journal of Child and Adolescent Psychopharmacology. 2016;26(10):939-94

14. Potter David. Growth and Morphology of Medicinal Cannabis. The medicinal uses of cannabis and cannabinoids. Pharmaceutical Press, 2004. 